\title{
Nuclear qualification process for systems, structures and components
}

\author{
Vladislav Gvozdev ${ }^{1, *}$, and Galina Kozinetc ${ }^{1}$ \\ ${ }^{1}$ Peter the Great St. Petersburg Polytechnic University, Polytechnicheskaya 29, St. Petersburg, \\ 195251, Russian Federation
}

\begin{abstract}
The modern NPPs (Nuclear Power Plants) are the part of the very complex and demanding sector of industry. Its complexity is based on the innovate and the high-tech technologies, engineered safety features where the specific safety functions are to be performed to ensure the nuclear safety (as part of technosphere safety) and prevent radioactivity release, which consequently lead to the possible human losses and environmental disasters. Consequently, modern technologies incorporated in the design and construction of NPP (its systems, structure and components) shall be qualified to ensure its capability to perform designated safety functions in the demanded conditions, including harsh accident environment (qualified as intended) via the specific V\&V activities. Thus, Qualification should not cover only the equipment, but the all: systems, structures and components (SSC), therefore a systematic approach to its organization and planning is needed, which is not fully presented in publications nowadays. The article objective is to define the SSC Qualification and its scope of application, identify the Functional and Environmental qualification and forming of the Qualification context. Then, the article determines the $\mathrm{V} \& \mathrm{~V}$ actions that provide Qualification evidences.
\end{abstract}

\section{Introduction}

The modern NPPs (Nuclear Power Plants) are the very complex and demanding industrial civil facilities. their complexity is based on the innovate and the high-tech technologies, engineered safety features where the specific safety functions are to be performed to ensure the nuclear safety (as part of technosphere safety) if the incident or accident will accrue at the NPP. The importance of guarantee of such safety functions fulfillment were based on the dangers of the nuclear industry, when the violation of nuclear energy producing technology can lead to the risk of radioactivity release which consequently lead to the possible human losses and environmental disasters. [1-3]

The biggest of the nuclear accidents were: Three-Mile Island NPP accident in the USA in 1979, Chernobyl NPP accident in 1986, Fukushima-1 NPP in Japan in 2011. These and the less significant accidents and their analyses [4] make the nuclear industry the most

\footnotetext{
* Corresponding author: vladislav.p.gvozdev@gmail.com
} 
demanded. The innovate and best technical solutions are the part of NPPs Design, the modern technologies are used during their construction [5]. Thus, modern NPPs are designed to stay safe under any external and internal impacts, such as: floods, hurricanes and tornadoes with a wind speed of up to $56 \mathrm{~m} / \mathrm{s}$, crash of heavy commercial airplane on a speed of $200 \mathrm{~m} / \mathrm{s}$, earthquakes with magnitude up to 8 , shock (blast wave) with a pressure of $30 \mathrm{kPa}$ and for failure mode of any internal processes (based on the personnel or software errors, equipment failure, etc.). [6-7]

To achieve such technological level the strictest requirements, which were reconsidered and stiffened after abovementioned incidents to be implemented during NPPs Design and Construction, further, requirements fulfilment to be justified. Verification and validation process $(\mathrm{V} \& \mathrm{~V})$ is used for confirmation of requirements compliance. This process was widely investigated in articles and publications: in general in the [8-10], and in the different industry areas (e.g. for hydropower units in [11]). For the nuclear business Project Management Body of Knowledge [9] provides the general approach, and the IAEA (International Atomic Energy Agency) provides the specific requirements to the V\&V in the safety standards (such as [12-14]) as part of the management system. Specific areas as the nuclear testing verification [15], equipment and civil structures V\&V against the safety requirements in the [16-17].

However, in such complex civil facilities as NPP the V\&V serves for confirmation of any requirements fulfilment (with focus on safety) $[14,16,18]$. Partially V\&V results are used for the justification of the safety functions fulfilment, what is the target of Nuclear Qualification as the particular type of $V \& V$, focusing of ensuring of the complex safety of the civil facilities and their functions.

Generally, qualification as the process is applied for the different industry sectors were the functions are the core [8-9]. (e.g. it used for the medical products for human use as presented in [17]). But its application is different then in the nuclear sector, where safety is the top priority, and losing of the safety functions can lead to the technosphere disasters [18], thus this area shall be carefully investigated. Generic requirements and reviews for nuclear facilities qualification is presented in the IAEA publications [14, 19, 20]. Different methods are used for assessing of the state of equipment qualification (e.g. method of assessments for Ukraine NPPs is presented in [21]), disciple specific requirements for equipment qualification (mostly for electrical and I\&C equipment which were compared in [22]) could be found in the international regulations (e.g. for electrical equipment in [23]).

At the equipment level the qualification issues were reviewed in the conformity assessment field [24-25], which is also lead to the guaranty the equipment compliance with the safety requirements. But conformity assessment scope is mostly oriented to the equipment (components) level, and compliance with the safety requirements of all equipment within the system cannot guarantee the fulfilment of the safety function of the whole system.

Thus, considering fact that to achieve the NPP safety and to avoid any negative impacts on humans and environmental (and the technosphere disasters in the most serious cases), Qualification shall be performed for the Systems, Structures and Components at the on the system and equipment levels [14], abovementioned publications were focused on the equipment V\&V and Equipment Qualification.

Equipment is performing their functions as part of system, and fulfilment of the functions of all equipment within the system does not guarantee fulfilment of the system functions as the whole. The V\&V for the system and complex NPP Qualification were not widely investigated, some publications are available (e.g. issues regarding systems and modelling and their verification is presented in [26]), but they not cover the nuclear special aspects. 
The issue for the NPP Qualification, which biggest part to be performed during the NPP Design and Construction, especially on the System level was not investigated in detail yet. Equipment level qualification data shall be systematized to create strong system of Qualification for such complex civil facilities as NPP.

Thus, the nuclear Qualification process for the Systems Structures and Components (SSC) is crucial for the NPP Safety, where safety functions performance shall be justified during the NPP Design and Construction. Based on this the objectives of this work are as follows:

1. Define and formulate the Nuclear Qualification definition and its scope of application for the NPP Design and Construction;

2. Identify the Functional and Environmental Qualification to verify fulfilment of the SSC safety functions.

3. Define the main sources of Qualification Evidences (Qualification measures), which will be sufficient to justify the Safety functions fulfillment.

\section{Methods}

In the course of the Nuclear Qualification survey used at the NPP Design and Construction phases the following method was applied:

- International requirements for the Nuclear safety and safety functions were studied to specify the objectives of Functional Qualification.

- Various V\&V processes of design solutions applied in the course of their application to the NPP safety functions fulfillment were analyzed.

- Conditions for the safety functions was analyzed to determine the environmental qualification.

\section{Results and Discussion}

According to the general requirements to the NPPs $[1,14,19]$ and their SSCs the NPP design and construction contains several reliable levels and methods of protection (based on the defense in depth principles (DiD)) to prevent the release of radioactivity beyond the plant. Protection is achieved through the use of numerous design provisions (implemented in addition to standard technological processes for the electricity production (normal operation functions)) that aim to prevent the loss of safety functions under the influence of internal or external hazards, initiating events, which can be cause for violation of normal operation and failures of components (one or more), systems and structures.

Consequently, modern technologies incorporated in the design and construction of NPP (its systems, structure and components) shall be Qualified to ensure capability of the SSCs to perform designated safety functions in the demanded conditions, including harsh accident environment (qualified as intended) via the specific V\&V activities (e.g. testing, analyses, calculations, etc.), focused on the safety functions.

Thus, qualification shall consider two main elements: Function of SSC and Conditions (postulated conditions) where this function shall be performed. Such conditions, which shall be considered in the design and consequently qualified, could be:

- Dynamic impacts, including the seismic impacts and the airplane crash - SSC (passive and/or active SSC, especially civil structures and buildings) shall demonstrate the ability to perform its required safety role during and/or after the time it is subjected to the forces (earthquake and airplane crash response spectra);

- Environmental conditions (e.g. vibrations, radiological and steam conditions associated with pipe breaks based on loss of coolant (LOCA), high energy line break (HELB) [27]) conditions which are results of the initiating events where SSC shall perform their function. 
Such conditions are typically considered as the part of Information model of civil facility and linked to the 3D Model (Building Information Modeling).

Considering abovementioned elements, the definition of the Qualification of NPP can be formulated as following:

Qualification of SSC is a process of obtaining evidences (Qualification records) of the capability of the Qualification items to perform the functionality or purpose as intended (Functional qualification) in a specified physical environment (seismic and environmental qualification). Elements of qualification may include: safety assessments, operational experience, analysis, tests, etc.

Environmental Qualification and the Dynamic Impacts Qualification (more often referred together as Environmental qualification) is the part of Qualification discipline, which is focused on the obtaining the evidences that qualification items are suitable to perform their functions (functional operability and/or structural integrity will be maintained) in specified conditions (e.g. vibration, temperature, pressure, radiation, humidity) existing before, when and after they are required for the Plant entire design service life-cycle.

To handle the SSC nuclear Qualification in systematic manner the following dimensions shall be taken into account:

- Nature of qualification items - as presented in the introduction part of the article, different disciplines is covered by the Qualification requirements and reviewed in scientific publication differently, nevertheless all of them shall be covered by Qualification. The considered disciplines are: Mechanical (Process), Instrumentation and Control (I\&C), Electrical, Civil. In some cases, SSC could be presented as combination of different disciplines (e.g diesel generator which have their own mechanical parts, electrical components, their own I\&C systems and performs their own function (power supply)). Such cases shall be qualified separately.

- Hierarchy of qualification items - Qualification shall be performed at the component level when the function of equipment shall be qualified, and on the system level, when the function of the whole system shall be performed and qualified, including the function of all equipment therein. In some cases (e.g. I\&C) in addition to the system level the architecture level shall be qualified (as the connection and interconnection of systems, switching of their functions, based on the commands, etc., [22]).

- Phase - Qualification is applicable for the whole life-cycle of the NPP, but the most crucial is the stage of NPP Designing, where DiD principles are to be implemented, where all possible initiating events, hazards considered, and aging (including the thermal and ionization emission aging) are considering in the Design. Such technical solutions and their reliability shall be qualified for the whole life-cycle of operation, till the decommissioning. Qualification of the NPP Design can be divided on the different phases: first the Design as is, when the NPP is exist only on paper, and qualification methods are: calculations, modeling, analyses (probabilistic and determenistic), then Construction and the Erection of NPP where all of the design solutions to be realize physically. And the quality of their realization is crucial. Therefore, SSC shall be qualified again at the Construction phase using the tests, examinations and different types of control [28-32].

The combinations of the above stated dimensions can be considered as the Qualification context and its scope of application. The specific V\&V measures (which provide qualification evidences) to be planed using the same context. Such V\&V are:

- QA of design and manufacturing processes;

- Tests and inspections;

- Safety assessments;

- Operational experience;

- Analyses. 
- Combination of above stated V\&V

Planning and implementation of the SSC Qualification and $\mathrm{V} \& \mathrm{~V}$, providing qualification evidences in such manner can cover any safety functions at any levels and consequently their implementation at the all stages of NPP Design and Construction provides confirmation of safety functions fulfilment in any possible variations and Nuclear and Technosphere safety will be achived.

\section{Conclusions}

Thus, following the foregoing objectives and methods, during the research the following results have been achieved:

1. Due to complexity of the NPP Design and Construction to prevent the release of radioactivity beyond the plant the specific safety SSC are designed using the DiD principles. Such SSC shall be suitable to perform their functions as intended in justified manner. Qualification is one of the methods to ensure its capability to perform designated safety functions in the demanded conditions, including harsh accident environment via the specific V\&V activities providing qualification evidences to ensure the nuclear safety, as part of Technosphere safety.

2. Qualification of SSC was defined as a process of obtaining evidences (Qualification records) of the Qualification items capability to perform their functionality or purpose as intended (Functional qualification) in a specified physical environment (Environmental qualification).

3. The scope of application of qualification and corresponding V\&V is its context, which consist of the following dimension: Nature, Hierarchy and Phase of qualification items. The combinations of Qualification dimensions form it scope of application and can provides confirmation of Nuclear and Technosphere safety in any possible variations.

\section{References}

1. V.A. Sidorenko Safe use of atomic (nuclear) power (nuclear safety), (2013), pp 16211630

2. I.Hotynchan, Tkachenko I. Analysis of ensuring safety at nuclear power plants, (2015)

3. R E Hester, R M Harrison Nuclear Power and the Environment (2011)

4. A.V. Yablokov, V.B. Nesterenko, A.V. Nesterenko, Chernobyl: Consequences of the Catastrophe for People and the Environment, (2007).

5. Official web-site of ROSATOM State Atomic Energy Corporation URL: http://www.rosatom.ru/

6. under general editorship of E. V. Ametistova, Fundamentals of the modern power industry, (2008). (RUS)

7. V.A. Sidorenko Safety of Atomic (Nuclear) Power Use (Nuclear Safety), (2012), pp 317, (RUS)

8. J.Gerace, Understanding verification and validation of product model data in industry, (2013);

9. IEEE Guide--Adoption of the Project Management Institute (PMI(R)) Standard A Guide to the Project Management Body of Knowledge (PMBOK(R) Guide), Fourth Edition;

10. P.Roache Verification vs. Validation. Mechanical Engineering, (1995);

11. G.Kozinetc, Magazine of Civil Engeneering, (2012). pp. 30- 37 (RUS); 
12. IAEA Safety standards Series No. GSR Part 2, Leadership and management for safety (2016);

13. IAEA Safety standards Series No GS-G-3.1, Application of the management system for facilities and activities, (2006);

14. INSAG-12 Basic safety principles for nuclear power plants: 75-INSAG-3 rev. 1 / a report by the International Nuclear Safety Advisory Group. - Vienna: International Atomic Energy Agency, (1999).

15. J. F. Evernden Verification of nuclear testing, (1985). pp 792a-794

16. M.El Baradei Ensuring nuclear safety \& security, (2001). pp 32-33.

17. M.M.Nesterchuk, V.A. Lebedynets, A.V. Bursakov Qualification of the equipment in pharmaceutical pro-file laboratories, (2009), pp 17-22.

18. M.S.Baxter Commercial nuclear power, assuring safety for the future journal of environmental radioactivity, (1999), pp 106-108

19. NE-BP Nuclear energy basic principles. International Atomic Energy Agency, (2008).

20. Safety reports series \#3, equipment qualification in operational nuclear power plants: upgrading, preserving and reviewing, International Atomic Energy Agency, (1998)

21. I.A.Ostapenko, D.V. Goranchuk, D.M. Kosyak Methods of assessing the current state of equipment qualification in Ukrainian NPPs, (2012), pp 8-11

22. CEC Qualification Benchmark Group. Comparison of European Practices for the Qualification of Electrical and I\&C Equipment Important to Safety for LWR Nuclear Power Plant, (1992)

23. IEC/IEEE 60780-323, Nuclear facilities - Electrical equipment important to safety Qualification, (2016)

24. V.A.Barvinok, L.A. Naumov, A.V. Dolgikh, Increase of the role of conformity assessment at the facilities controlled by the federal service on ecological, technological and nuclear supervision, (2012), pp 226-232, (RUS)

25. A.S. Pecherkin, Perspektivy razvitiya edinoy sistemy otsenki sootvetstviya na ob"ektakh. Podkontrol'nykh rostekhnadzoru, (2009), pp 9-10 (RUS)

26. R. D. Adcock et al, "Representing Systems with Models", "System Verification", and "System Validation" in: BKCASE Editorial Board. (2015);

27. Safety Guide, Safety Series No. 50-SG-D11 General Design Safety Principles for Nuclear Power Plants, International Atomic Energy Agency, Vienna, (1986).

28. S.Ya.Petrov, V.I. Afanasyev, A.D. Melnik, M.I. Mironov, A.S. Navolotsky, V.G. Nesenevich, M.P. Petrov, F.V. Chernyshev, I.V. Kedrov, E.G. Kuzmin, B.V. Lyublin, S.S. Kozlovski, A.N. Mokeev, Probl. At. Sci. Technol. Ser. Thermonucl. Fusion 39 (1) (2016)

29. M.S. Khvostova Power Technol. Eng. 45 (6) (2012)

30. Z. Bazaras, B.Timofeev, N.Vasilieva, N.Bykovskiy, R. Kersys, L. Raslavicius, Intelligent Technol. Logist. Mechatronics Syst., ITELMS - Proc. Int. Conf. (2011), pp. 29-32.

31. L.B.Getsov, B.Z. Margolin, D.G. Fedorchenko, Mater. Tehnologije 42 (6) (2008)

32. V.I. Grigor'ev, O.E. Piskun, V.M. Ivanov, Teoriya i Praktika Fizicheskoy Kultury (2015) 